\title{
PARASITISMO INTESTINAL EM ESCOLARES, NA ILHA DO GOVERNADOR, RJ (1977-1979)
}

\author{
Carlos Vinha * \\ Maria Regina de Souza Martins * *
}

\begin{abstract}
Na liha do Governador, R.J., uma pesquisa de 1977-79, em 25 escolas municipais, 2 particulares e 1 colônia de férias conseguiu levantar a incidência de parasitoses intestinais em 7.507 crianças. Verificou um parasitismo global de $60.7 \%$; a ascaríase em $29.2 \%$ dos examinados; tricuriase em $37.3 \%$; giardíase em $8.4 \%$, com ampla variação de escola para escola, em consonância com a localizacão, clientela (proximidade de áreas faveladas), conjuntos habitacionais, colônias de pescadores etc. Os Aa nessa pesquisa pessoal, particular, voluntária procuram chamar a atenção das autoridades de saúde püblica, educacionais e órgãos ligados á nutrição sobre as possobilidades de serem criados programas e campanhas destinadas a reduzir, eliminar, controlar, equacionar essas questões, que afetam sobretudo a criança em fase de desenvolvimento físico e mental. Sugerem os Aa que uma parte das disponibilidades utilizadas na suplementação alimentar aos escolares, se não houver outro meio de autonomia, seja empregado para o diagnóstico e tratamento dos parasitados nas comunidades consideradas prioritárias para este tipo de campanha de massa, dado que o parasitismo intestinal prejudica sensivelmente e especialmente o desenvolvimento hamónico das crianças alta $e$ cronicamente infectadas, prejudicando-as em seu desenvolvimento físico e mental, aproveitamento nos estudos, lesando-as muita vez para toda a vida. A alta eficácia dos antelmínticos e parasiticidas especificos (contra a ascariase por ex) e os antianêmicos (sais ferrosos) permite viabilizar cam. panhas de massa. A formação de um voluntariado em uma campanha com essa característica, nos moldes da realizada no Japão contra a ascariase, deveria ser tentada e estimulada. Essa campanha ou campanhas deveriam começar pelas escolas e prosseguir atendendo os pré-escolares.
\end{abstract}

O parasitismo intestinal, as helmintíases especialmente, são uma constante no meio interno do homem brasileiro, em quase todos os quadrantes.

Desde há muito deixaram de ser objetivo de pesquisas e estudos, números $e$ incidências, quase sempre repetitivas, e que pouco adiantavam em relação à solução desses problemas de saúde pela constância daqueles desvalores. E a maior parte das observações, realizadas por pesquisadores particulares, em comunidades pouco expressivas, nem sempre muito significativas para a extensão do problema, sem continuidade no tempo e no espaço por ausência de suporte financeiro adequado, sem apreciação global, impossibilitaram acompanhar nessas mesmas comunidades, as tendências e perspectivas de equacionamento dessas questões. Inclusive os estudos e levantamentos de índices etc, não se traduziram ainda objetivamente por medidas e campanhas que as levem em consideração em profundidade e seriedade.

Não houve nem há ainda, uma programação integral em qualquer nível, federal, estadual, municipal, que se proponha a estudar e esquematizar atividades específicas contra essas doenças, a fim de que não nos deparemos apenas com dados estatísticos de frequência e incidências, mas proponham e executem medidadas terapêuticas e profiláticas específicas que possam atingir o âmago dessas questões.

$O$ presente trabalho não foge infelizmente a algumas dessas contingências e restrições, embora nosso interesse seja o de permitir ou registrar uma continuidade de observações em anos sucessivos na llha do Governador, que gerem com a preocupação pelos números encontrados, dados adicionais e referências aos riscos dessas doenças, a conscientização desses mesmos problemas e uma possível e remota preocupação adicional entre os elementos da

\footnotetext{
* Médico Sanitarista - Sucam - Min. da Saúde.

* Médico
}

Recebido para publicação em 16.2.1979. 
própria comunidade e das autoridades sanitárias, que tenda à programação de medidas e campanhas recomendadas para o equacionamento desses problemas.

Os dados coletados na IIha do Governador, Rio de Janeiro, durante os anos de 1977 - 79, de parasitismo intestinal em escolares de escolas municipais, têm como escopo: chamar a atenção de autoridades sanitárias, educacionais e de nutrição para essas doenças, fazer sentir o contigente de pessoas atingidas e por atender, mesmo em comunidade relativiamente saneada e de bens padrões econômico-sociais como soi ser a llha, procurando demonstar os riscos e prejuízos para os atingidos, traçando ou procurando esclarecer possibilidades de atendimento pelo menos a algumas parasitoses mais sensiveis a campanhas específicas, e a relativa facilidade dessas medidas como o exame coproscópico, a medicação periódica e sistemática das crianças parasitadas durante o ano letivo e, se possivel, incluir nessas pesquisas, com o tempo, o estudo e análise de fatores como índices de hemoglobina, variações ponderais $\mathrm{e}$ estaturais das crianças verminadas e das desparasitadas, sob a influência e recebendo merenda escolar, sopa etc. Além disso, a ministração de cursos, palestras etc, nas escolas e para os pais e responsáveis pelas crianças, com a finalidade de incutir conhecimentos e responsabilidades. Nosso objetivo maior seria o de também criar condições e preocupações para o mesmo problema em outras áreas de nossa cidade, em outros bairros, sobretudo naqueles onde sabemos mais vulneráveis as condições econômicas e de assistência médico-sanitária, e que se traduzissem em medidas coerentes e adequadas $\mathrm{e}$ inclusive possam ser aplicadas em outras áreas e comunidades.

Durante três anos (1977-1979), os Aa realizaram uma pesquisa em escolas municipais da Ilha do Governador, para verificar a incidência de parasitoses intestinais em escolares.

A llha do Governador $\left(29 \mathrm{Km}^{2}\right.$ de superfície e cerca de 130 mil habitantes) está localizada na Baia da Guanabara, Rio de Janeiro, e conta com uma rede escolar de cerca de 50 escolas e colégios, municipais (25), estaduais, a Universidade do Fundão etc. As escolas municipais (públicas) com uma frequência de cerca de 21000 alunos constituiram nosso objetivo, clada a sua clientela presumivelmente mais necessitada, e entre os alunos dessas escolas foram examinados os das primeiras séries preferentemente, habitualmente também os mais carentes e a exigirem maiores atenções.
Examinadas 7.507 crianças das 25 escolas municipais, de uma escola mantida para filhos de operários da Ponte Rio - Niterói e de uma Creche Casulo e crianças participantes de uma Colônia de Férias no Corpo de Fuzileiros Navais, na llha do Governador. Durante o periodo realizamos mais de 200 palestras para pais e responsáveis, antes de iniciarmos e durante as atividades em cada escola a ser trabalhada.

Utilizamos sempre o método de Hoffmann, Pons e Janer.

Verificamos em resumo:

\begin{tabular}{|c|c|}
\hline Coproscopias . . . . . .7.507 & $\%$ \\
\hline Positivas . . . . . 4.558 & 60.7 \\
\hline c/ áscaris . . . . . 2.192 & 29.2 \\
\hline c/ tricúris & 37.3 \\
\hline c/ ancilost. & 3.5 \\
\hline c/ oxiúros & 1.4 \\
\hline c/ Schist. mansoni. . 19 & 0.3 \\
\hline c/ himenoleps sp . . . 27 & 0.4 \\
\hline c/ ameba cóli . . . 622 & 8.3 \\
\hline c/ giárdia . . . . & 8.4 \\
\hline Negativos. . . . . . 2.949 & 39.3 \\
\hline
\end{tabular}

\section{RESULTADOS}

1) Os 7.507 exames coproscópicos de escolares de todas as escolas públicas da llha do Governador representam cerca de $35.7 \%$ das crianças matriculadas nessa escolas, o que nos permite com razoável aproximação, a avaliação da incidência de parasitoses intestinais entre essas crianças. Tanto quanto possivel os exames foram realizados entre alunos das 3 primeiras séries, isto é, em crianças de 6 a 9 anos.

2) A existência de algum parasita intestinal em escolares, na llha do Governador, foi constatada em 4.558 crianças, o que dá a média de $60.7 \%$. A mais elevada (83.5\%) encontrada na Escola Nossa Sra do Loreto, na praia de Itacolomi, colônia de pescadores. A Creche Casulo do Dendê na favela do mesmo nome $(81.3 \%)$. As incidencias decrescentes, as mais elevadas, foram observadas em escolas próximas ou servindo a favelas ou áreas semifaveladas. As menores incidências globais foram constatadas em escolas situadas em conjuntos habitacionais recentes e em bairros exclusivamente residenciais, com perfeito saneamento e um bom nível econômico-cultural dos moradores: assim mesmo o menor desses índices, $42.4 \%$ na Escola Costa Rica, está longe de ser considerado razoável ou desejável. Em termos gerais, as incidências encontradas parecem condicionadas ao saneamento ambiental, proximidades de grupa- 
mentos semi-favelados etc., e permitem estabelecer com bastante realismo as condições do saneamento e os padrões sanitários de cada uma das comunidades a que a escola serve.

3) Ascariase - 29.2\% dos alunos examinados são protadores-doentes de ascaríase. As maiores incidências forami verificadas em escolas situadas em Tubiacanga e Itacolomi, colônias de pescadores: Escola Guilherme Presser (50.8\%) e Alberto de Oliveira (50.7\%). As menores incidências nas Escolas Gurgel do Amaral (10.9\%), Lavínia Dória (15.5\%), Rodrigo Otávio (16.6\%). Em relação à ascaríase deve ser referido que as palestras preliminares, às vezes realizadas para pais e responsáveis, alguns dias antes da coleta do material para exame, orientam os pais mais cuidadosos e atentos a que mediquem seus filhos etc., com ascaricidas de dose única falseando talvez os resultados. Apesar do incoveniente para uma boa avaliação da incidência daquela verminose, devemos nos congratular com as possibilidades e vantagens desses esclarecimentos preliminares que ajudam a superar o problema. A gama de incidências observadas nas escolas retrata um dos mais expressivos problemas de saúde pública atual, em termos nacionais.

4) Tricuriase - Considerada relativamente inexpressiva como agente de males e danos ao portador, essa helmintíase se apresenta com maiores índices que a ascaríase, nos escolares da Ilha do Governador. Sua incidência global $(37.4 \%)$ e por Escola apresentam esta característica. Contribui para tal fato provavelmente a inexistência de um tricuricida capaz de eliminar o helminto com dose única o que não ocorre com a ascaríase. Maior incidência verificada na Escola Guilherme Presser $(64.1 \%)$, localizada em Tubiacanga, colônia de pescadores. A seguir, a Creche Casulo do Dendê (62.5\%) na favela do mesmo nome. As menores nas Escolas Rodrigo Otávio (22.5\%). Maestro Francisco Braga $(24,9 \%)$, Guergel do Amaral (26.9\%), em conjuntos habitacionais modernos, etc. As incidências desta helmintíase coincidem cum as da ascariase, para as mesmas escolas, embora ligeiraniente mais elevadas. Também registrada em todas as Escolas.

5) Giardiase - Em ordem de frequência comparece esta protozoose intestinal em 3. lugar com uma incidência de $8.4 \%$ para todas as crianças examinadas. Não existem as grandes flutuações de incidências encontradas em outras helmintiases. Maior frequência nas Escolas Loreto Machado (14\%), seguida de Abeilard Feijó (13\%), na Creche Casulo Dendê (12.5\%), Lavínia Dória (12.2\%). As menores nas Escolas
Maestro Francisco Braga (3.6\%), Centro Ocupacional Rotary $(4.3 \%)$, Guilherme Presser $(5.5 \%)$.

6) Ancilostomose - Encontrada com uma incidência global de $3.5 \%$ para todos os exames (263 positivos em 7.507), esta helmintíase não foi observada em alunos de 2 escolas e da Creche Casulo. Os maiores indices nas Escolas Loreto Machado (10.4\%), Jorn. Orlando Dantas (9.6\%) e N. Sra do Loreto $(9.3 \%)$, poderiam caracterizar as precárias condições de saneamento ambiental ou econômico-culturais das comunidades onde estão localizadas estas escolas, Itacolomi, Dendê. Algumas escolas (6) com 1 portador apenas, talvez demonstrem a tendência que se observa para o desaparecimento desta helmintíase como doença autóctone nas áreas que vão sendo saneadas. $E$ pode ser observado na llha do Governador' onde verificamos que algumas das crianças com o helminto devem provir de comunidades do interior, já infectadas, posto que muitos dos moradores das favelas e semi-favelas da Ilha (13 favelas) são famílias mineiras, nordestinas, de zonas rurais do próprio Estado do Rio de Janeiro. As sofríveis condições de saneamento nesses locais, o uso de latrinas e de fossas etc., nessas favelas, embora distantes de ideais, impedem o contato direto do homem ou criança com o material fecal infectante e elimina-se assim o elo epidemiológico da doença.

7) Oxiuríase - Encontrada em 106 crianças (1.4\% de positivos em 7.507 examinadas). A técnica empregada (Hoffmann, Pons e Janer) é imprópria para o diagnóstico dessa helmintiase, e que se calcula várias vezes maior. Maiores incidências nas Escolas Jorn. Orlando Dantas $(3.3 \%)$, Sun Yat Sen $(3.0 \%)$, Cuba $(2.8 \%)$. As informações das próprias mães, durante as palestras que realizamos, levam-nos a admitir que esses números devem ser muito maiores que os registrados.

8) Esquistossomose - 19 alunos provenientes de Minas e do Nordeste apresentaram-se com Schistosoma mansoni, o que dá uma incidência geral de $0.3 \%$.

9) Himenolepiase - Esta teníase foi observada em 27 crianças de 10 Escolas e da Colónia de Férias do Corpo de Fuzileiros Navais (8 casos). Embora benigna, com tendência do desaparecimento espontâneo, fica o registro.

10) Multiparasitismo Observa-se número expressivo de crianças multiparasitadas, especialmente por áscaris e tricúris. Em 7.507 exames, 2.659 foram positivos para um (1) parasita intestinal (35.4\%). $\quad 1.522$ apresentram 2 parasitas $(20.3 \%)$. 347 revelaram 3 parasitas concomitantemente $(4.6 \%)$. 30 crianças era portadoras 
de 4 parasitas e 1 de 5 .

11) Tratamento específico - Ao receberem o "Resultado do exame coproscópico "e durante as palestras, os pais e responsáveis são orientados para o tratamento gratuito no Centro de Saúde Necker Pinto, no Hospital N. Sra do Loreto, no Inamps etc., na liha, ou sob nossa orientação, opcional e gratuitamente.

12) Educação para a saúde - Durante toda a programação, em três anos de atividades na l lha do Governador, tivemos oportunidade e interesse na divulgação em palestras a pais e responsáveis em cada uma das escolas trabalhadas, alguns conceitos básicos a nosso ver indispensáveis para melhor orientação e conscientização do problema. O nivel cultural dos pais e a relativamente boa condição econômica da maior parte das famílias influiram, e supomos para um saldo positivo nestas palestras e debates, visivel nas escolas situadas em comunidades melhor providas, e seguidas de uma ligeira queda dos índices da ascariase, helmintíase mais sensível a uma campanha de massa. Não devemos contudo esperar demais de um programa de educação para a saúde, posto que sensibilisa por pouco tempo quando sensibilisa, $e$ inclusive observa-se a tendência de abrandamento do impacto inicial, com o decorrer do tempo. As campanhas contra as parasitoses intestinais devem ser ativas, dialogadas com pais e responsáveis, examinando crianças, tratando-as, exigindo colaboração e não apenas traçando planos, mostrando filmes, slides, projeções, divulgando prospectos, enegrecendo riscos etc, Embora contribuam, proporcionem talvez colaboração $e$ boa vontade $e$ alguns dividendos que podem ser até eleitorais, a educação para a saúde, mesmo visando a criança para as quais evidentemente existem fatores de boa receptividade de pais e responsáveis e de autoridades, tem suas limitações e apenas a ação enérgica, continuada, vigilante de órgãos competentes e unidades ativas, consegue resultados palpáveis, satisfatórios. Mais difícil, parece-nos, é conquistar autoridades sanitárias, administrativas, que proporcionem recursos, interessem-se, colaborem ou simplesmente admitam ou convenham que tais campanhas se realizem. Para essas pessoas, para tais autoridades devem ser dirigidos os esforços, os esclarecimentos, a relação dos riscos e males, as possibilidades, perspectivas de campanhas de massa ou de simples atendimento ao estilo do que tivemos oportunidade de realizar neste nosso trabalho.

13) Discussão sobre o parasitismo intestinal em nossos escolares - Mesmo sob risco de sermos considerado repetitivo, monocorde, unius libris etc., os niveis de parasitismo e a importância que julgamos deve ser dada aos problemas das parasitoses intestinais esclarecem as ênfases e repetições que costumamos dar no trato dessas questões. Afinal nosso compromisso é apenas com o acampamento global, com a comunidade e esperamos que os conceitos que aqui expendermos, e não são nossos apenas, sirvam e sejam considerados úteis, permitam estudos e programações, orientem pesquisas e trabalhos e transformem-se em realizações concretas, práticas, objetivas, finais.

Sabemos o descaso às disciplinas de saüde pública e de parasitologia em nossas academias e escolas de medicina. Evidentemente, um reduzido contigente de profissionais responsáveis por problemas de saúde pública, implica em menor pugilo dos que se poderiam se envolver em algum problema específico. $E$ entre estes situa-se o das parasitoses intestinais. Como a prioridade não é ditada por algum aiatolá, os poucos que se aventuraram a ventilar questões para as quais não há consenso unânime, sentem-se desamparados, sem diálogo, sem audiências e anuências. Nosso proselitismo não atinge as esferas decisórias, que poderiam tornar realidade e possíveis os programas que julgamos óbvios, exequiveis, necessários.

Mas partamos para as considerações:

a) As parasitoses intestinais são doenças, os vermes e os protozoários que podem se albergar em nossos intestinos e provocam males, devem ser eliminados, erradicados. Pelo simples fato inclusive de que provadamente não se conhece ainda benefício proporcionado por qualquer um deles. São corpos estranhos, elementos espúrios, consequência e resultados ainda de nossa evolução social e biológica e que as comunidades mais progressistas tendem a eliminar. Somos ainda o último refúgio de espécies animais incapazes de sobreviverem por conta própria, em ambientes naturais, e que embora limitem ao mínimo danos e prejuízos ao meio e elemento protetor, não destruírem o seu "habitat", passarem despercebidos, devem ser eliminados, tratados como fonte potencial e real de prejuizos para o parasitado, e definitivamente considerados inimigo natural do homem e da comunidade.

b) As parasitoses intestinais raramente são registradas em obituários. São doenças que se tornam crônicas pelas reinfecções subintrantes dos moradores em comunidades desprovidas ou carentes de satisfatório saneamento ambiental etc. Os danos específicos de cada uma das parasitoses capazes de produzirem distúrbios orgânicos dependem de fatores confluentes adversos 
como condições de vida e de moradia impróprias ou deficientes, hábitos anti-higiênicos, carências alimentares, insuficiente ou ausência de assistên. cia médico-sanitária etc, do parasitado e da própria comunidade, como um todo.

c) A ação maléfica dos parzsitas intestinais capazes de produzirem doenças se faz sentir compreensivelmente no sistema digestivo, na nutrição, desenvolvimento físico e mental etc. do indivíduo parasitado ou verminado, especialmente na criança em fase de desenvolvimento. Comprovadamente, observações sobre o desenvolvimento estatural e ponderal em crianças desparasitadas constataram ser sensivelmente maior entre as que recebiam sua merenda escolar que o daquelas que não eram desparasitadas embora recebessem a mesma merenda escolar. Nossos programas de alimentação do escolar (merenda escolar, leite, almoço, etc.) apesar de ajudarem substancialmente a vencer óbices sociais, econômicos, culturais, etc., que impedem a cada qual cuidar da alimentação dos seus filhos e crianças etc., incorrem em gravíssima falha ao não tentarem, ingnorarem, despreocuparem-se de eliminar do meio interno das crianças, de um dos maiores fatores de desperdício dos benefícios desse programa. A suplementação alimentar dada à criança, na escola, poderia, pelo mesmo preço, ser implementada, melhorada, proporcionar maiores benefícios se essa suplementação fosse dada a crianças desparasitadas. Sabe-se que uma parcela às vezes substancial do alimento ingerido serve também para a alimentação do verme ou parasita e muito é inaproveitado por ação tóxica etc. sobre o aparelho digestivo. Todos os alunos recebem diariamente uma daquelas suplementações alimentares na própria escola. Como, na llha do Governador, aproximadamente 2/3 dessas crianças de escolas públicas, são portadores-doentes de alguma parasitose intestinal $e$ comprovadamente essas infecções interferem por seus vários mecanismos na metabolização plena dos alimentos, há um evidente desperdício ou não-utilização dessas refeições e suplementações alimentares que representam para muitas crianças, a única refeição válida, nas comunidades e grupos mais carentes e economicamente vulneráveis.

d) O tratamento específico de qualquer parasitose intestinal constitui atualmente o mais adequado objetivo das campanhas de massa. Os modernos parasiticidas simplificaram extraordinariamente esse tipo de programa de saúde pública. Além da inocuidade desses produtos, sem manifestações colaterais, a notável eficácia em doses únicas, com resultados espetaculares na ascariase por exemplo, e o baixo custo, abrem perspectivas extremamente favorávies para o tratamento em massa.

e) Frequentemente se observa anemia ou pelo menos redução da taxa de hemoglobina em nossas crianças (em S. Paulo a quarta parte dos escolares examinados apresentaram esse tipo de problema), com a consequente e óbvia redução ou limitação da capacidade física ao nivel daquelas taxas. Esta questão deveria ser convenientemente estudada para que pudesse ser superada, tratada ou corrigida com a ministração de medicamentos e sais ferrosos, ou na própria alimentação e suplementação alimentar que seriam enriquecidas com sais ferrosos, sem que haja necessidade de complementações com vitaminas e outros sais minerais, que encarecem o produto sem melhorar-lhe a eficiência, pelo menos nos casos habituais com que nos defrontamos.

f) Poderia ser tornado obrigatório um exame coproscópico durante o ano letivo, acompanhado de desparasitação (2 ou 3 anualmente contra a ascaríase, ao menos). Uma parcela, preocupações, disponibilidades das campanhas de complementação alimentar deveriam ser destinadas a essa limpeza preliminar do meio interno das crianças, até que se obtivesse o controle definitivo dessas parasitoses. Pelo menos nas comunidades e/ou escolas nas quais as parasitoses intestinais ocorrem em niveis de alarına (mais de $50 \%$ das crianças infectadas) haveria de se cogitar de uma programação capaz de examinar e tratar todos os seus alunos com algum parasitismo uma vez por ano, ao menos.

Em relação às consequências da subnutrição etc., deve-se consignar que as crianças parasitadas apresentam-se também deficitárias no aproveitamento escolar (Biagi, 1970), com maior indice de repetências etc.

g) Como a escola reflete e traduz os índices, padrões e características da comunidade a que serve, percebe-se que sobraria um enorme contigente de indivíduos a serem atendidos e assistidos nesse setor de doenças transmissíveis, fora do âmbito da escola: o pré-escolar sobretudo, o que implica e envolve novas programações que os abranja etc.

\section{APRECIAÇÕES E SUGESTÕES}

A Ilha do Governador, área residencial da cidade do Rio de Janeiro, com uma população de cerca de $130 \mathrm{mil}$ habitantes distribuídos em várias comunidades, localidades etc., embora se apresente em sua maioria como bem saneada e 
com bons padrões de moradias, conjuntos habitacionais modernos, e bom nivel global de vida, mantém algumas comunidades sob condições precárias de saneamento como antigas colônias de pescadores no Itacolomi e Tubiacanga, cerca de 13 favelas de pequeno porte espalhadas por toda a liha. Estas condições, favelas dentro da Ilha e a proximidade de algumas das maiores favelas da Guanabara, na orla marítima que defronta a llha (Bonsucesso, Ramos, Manguinhos) embora tais favelas não devam provavelmente influir sobre a frequência e constância do parasitismo intestinal das crianças, também concorrem compreensivelmente para a diversidade e altas incidências encontradas entre os escolares provenientes desses grupos e núcleos populacionais.

O exame coproscópico de crianças de todas essas áreas, de escolares de escolas municipais mostrou uma incidência de $60.7 \%$ de positivos para algur:a espécie de parasita intestinal (helminto ou protozoário), notadamente de áscaris, trichuris, ancilostomídeo, tênia, esquistossoma, giárdia, o que deveria alertar e impressionar qualquer adminisı, ador sanitário mais atento, sobretudo para áreas e comunidades menos aquinhoadas no âmbito do nosso município, do Estado e do próprio pais.

O diagnóstico de uma parasitose intestinal, primeiro passo para uma campanha de massa, requer apenas pessoal, equipamento relativamente fácil de adquirir e manusear, e muito boa vontade e decisão para que possa funcionar. $E$ várias ou múltiplas unidades de trabalho, cada uma perfazendo sua cota de atividades. O tratamento específico ficou extremamente simplificado com os modernos ascaricidas e parasiticidas, em doses únicas ou em trếs e no máximo em dez dias de medicação (giáridia). Existe a possibilidade de controle e mesmo de erradicação do áscaris, bastando para isso um sistemático trata. mento trimestral seletivo (as crianças com áscaris receberiam esse tratamento) por ex, e ampla e constante campanha de esclarecimentos e orientação para pais e responsaveis. Nosso trabalho exclusivamente pessoal e compreensivelmente limitado não conseguiu senão atingir as primeiras etapas (levantamento de incidências, palestras, orientação para o tratamento). 0 detalhe final, a coroação do trabalho seria o exame global de todos os escolares, o tratamento dos parasitados e a continuidade desse tratamento durante e enquanto se mantiver qualquer parasitismo no grupo trabalhado. Longe de nós supor possivel a instituição de um voluntariado ou Assocação de Combate à Ascaríase por exemplo, como realizado pelos japoneses e que pos- sibilitou, a partir de 1946, cerca de 8.500.000 exames coproscópicos anuais, para levantamento diagnóstico e tratamento dos parasitadọs. Tal campanha conseguiu reduzir a incidência de $60 \mathrm{e}$ mais por cento de portadores-doentes de ascaríase para menos 0.5 por mil em 1976 , para todo o Japão, mediante o tratamento específico trimestral até que se conseguiu controlar a helmintíase e trazê-la a niveis residuais. Embora não se possa ou deva relacionar um fato a outro, a estatura média do japonez cresceu cerca de 5 centimetros neste mesmo período. Sugeriríamos fosse dada ênfase à participação de outros profissionais da área médica, laboratórios de análises clínicas que pudessem colaborar como voluntários nessa programação, em benefício da comunidade. Como não nos compete senão ponderar e propor, cogitar-se-ia em uma primeira etapa, da divulgação, informação, destaque, ênfase, para criar estímulos e emulações possíveis embora problemáticas.

Estamos consciente da exiguidade e limitações de nossos esforços diante da magnitude do problema. Além dos escolares e talvez mais necessitados, deveriam merecer cuidados os pré-escolares, enorme contigente de crianças menos assistidas - na escola a criança recebe sua merenda escolar, a refeição etc. - Apesar desse senão, não nos cabe sem dúvida alternativa - iniciarmos pelos escolares essa campanha, procurar atender toda a faixa de estudantes e a seguir, ou concomitantemente incluir o pré-escolar.

Nem todas as áreas e comunidades merecem talvez o mesmo tratamento. A prioridade deve ser dada às escolas situadas em locais de saneamento precário, onde moram pessoas de menores recursos econômicaos etc., onde se observam também os maiores índices de parasitismo intestinal. Nessas escolas, e em termos gerais em quase todas as de comunidades pobres, após levantada a incidência da ascaríse, por exemplo, deveriam os serviços de saúde pública, de saúde escolar etc., programar anual ou semestralmente uma desparasitação rotineira de escolares. Se apenas uma das refeições fosse substituída anualmente pela desparasitação de uma criança, em tese, visto como não há necessidade de se suprimir uma refeição, dado o relativamente baixo custo do medicamento (ascaricida por ex.), conseguiríamos melhores resultados $\mathrm{e}$ benefícios para a criança, do que alimentarmos comitantemente essa criança e os parasitas que ela alberga, sem que seja tomada qualquer providência de limpeza, saneamento, desparasitação do meio interno dessa mesma criança.

Transpondo para o âmbito nacional, conviria 
que os servicos de saúde, desde os locais aos estaduais e federais incluissem em suas programações campanhas contra as parasitoses intestinais, ampliando, corrigindo a incrível omissão de apenas se congitar da esquistossomose em campanhas do órgão federal responsável. Essas doenças, as parasitoses intestinais produzem maiores danos, cumulativamente, ao homem e à coletividade do que muitas doenças epidêmicas e endêmicas agudas ( e que merecem cuidados evidentementel pelo alto grau de infeccões e enorme dispersão, aliadas a fatores pessoais e culturais desfavoráveis - más condições de habita. bilidade, carências nutritivas ou curativas específicas na escala adequada. $O$ saneamento ambiental por exemplo, em condições ideais para uma comunidade rural só poderá ser obtido passo a passo, compreensivelmente, posto que lutamos ainda contra a proliferação de favelas, pela urbanização das mesmas etc., e não existem recursos para o que seria considerado requinte, o ideal.

Com a erradicação da malária, as parasitoses intestinais, doenças crônicas de nossas populações rurais e de comunidades marginalizadas em nossas cidades, assumiram a triste liderança de provocarem mais males que qualquer das doenças epidêmicas e endêmicas para as quais dispomos de amplo arsenal terapêutico ou profilático - vacinas, antibióticos, específicos, etc. De fato nem percebemos diretamente a existência e a ação e malefícios das parasitoses intestinais. A sintomatologia é pouco característica e muitas vezes subliminar, difícil de identificar. Quase sempre ligada sobretudo na criança a problemas de nutrição, tornando-os mais agudos ou expressivios, as parasitoses intestinais podem ser responsabilizadas pelo agravamento desses problemas sobretudo nos desnutridos ou malnutridos e carentes. Ao mesmo tempo que cuidamos em alimentar o escolar, deveriamos limpá-lo internamente, desparasitálo, torná-lo apto para se beneficiar ao máximo ou na medida desejável do repasto, alimentação, etc. que se proporciona à criança. Queimaríamos etapas no atendi mento ao indivíduo e seguramente, ao cuidarmos da criança rural ou mesmo cidadina, estariamos influindo para o futuro, diminuindo possivel mente o fluxo e volume de atendimentos dos serviços assistenciais às voltas diariamente com individuos provenientes de comunidades altamente parasitadas, lesados desde cedo em suas funções e sistemas orgânicos pelo parasitismo não cuidado, crônico, astenizante e que sói acompanhar desde o nascimento o nosso homem rural, continuando pelo suburbano, cidadino com estágios nas favelas e grupos marginalizados de nossas cidades. $E$ que numa triste apoteose traduzem-se em redução da capacidade vital, limitação do aprendizado, em crianças sem saúde, em jovens incapazes para o serviço militar, em adultos sem energia, sem horizontes, sem perspectivas e fadados à velhice precoce, inexorável. Evitaríamos ou ao menos tentariamos minimizar as lesões irreversíveis nas células nervosas das crianças permanentemente subnutridas, nas quais as parasitoses intestinais, direta ou indiretamente participam como concausas, prejudicando o desenvolvimento harmônico, normal, dessas mesmas crianças, inferiorizando-as irremediavelmente para a competição da vida e da própria sobrevivência. 
Ancilostomose em escolares - Ilha do Governador, RJ - 1977 - 1979

\begin{tabular}{|c|c|c|c|}
\hline Escola & Exames & $\begin{array}{l}\text { Positivos } \\
\text { p/ancil. }\end{array}$ & $\begin{array}{c}\% \text { de } \\
\text { positiv. }\end{array}$ \\
\hline 01 - Anita Garibaldi & 165 & 1 & 0.6 \\
\hline 02 - Álvaro Moreira & 224 & 4 & 1.8 \\
\hline 03 - Cuba & 579 & 14 & 2.4 \\
\hline 04 - Abeilard Feijó & 339 & 25 & 7.4 \\
\hline 05 - Rotary & 620 & 27 & 4.4 \\
\hline 06 - Sun Yat Sen & 336 & 9 & 2.7 \\
\hline 07 - Loreto Machado & 164 & 1 & 0.6 \\
\hline 08 - Alberto de Oliveira & 134 & 14 & 10.4 \\
\hline 09 - Pde José de Anchieta & 97 & 5 & 5.2 \\
\hline 10- Tte Antônio João & 254 & 7 & 2.8 \\
\hline 11 - N. Sra do Loreto & 97 & 9 & 9.3 \\
\hline 12 - J.I. Pedro Mendes & 170 & 1 & 0.6 \\
\hline 13- Guitherme Presser & 128 & 8 & 6.25 \\
\hline 14- Holanda & 738 & 37 & 5.0 \\
\hline 15 - Jorn. Orlando Dantas & 271 & 26 & 9.6 \\
\hline 16 - Rodrigo Otávio & 151 & 1 & 0.7 \\
\hline 17 - Costa Rica & 206 & 6 & 2.9 \\
\hline 18 - Cândido Portinári & 322 & 19 & 5.9 \\
\hline 19 - Didier B. Viana & 388 & 15 & 3.9 \\
\hline $20-$ Belmiro Medeiros & 255 & 3 & 1.2 \\
\hline 21 - Dunshee de Abranches & 328 & 19 & 5.8 \\
\hline 22 - Profa Lavínia Dória & 245 & - & - \\
\hline 23 - Gurgel do Amaral & 201 & - & - \\
\hline 24 - Maestro Fco Braga & 253 & 1 & 0.4 \\
\hline Centro Ocupacional Rotary & 116 & 1 & 0.9 \\
\hline Rio - Niterói & 169 & 4 & 2.4 \\
\hline Colônia de Férias C.F.N. & 541 & 6 & 1.1 \\
\hline Creche Casulo Dendê & 16 & - & - \\
\hline TOTA I S 7.507 & 7.507 & 263 & 3.5 \\
\hline
\end{tabular}


Parasitismo Intestinal em Escolares - Ilha do Governador, RJ - 1977 - 1979

${ }^{*}$ Escolas trabalhadas $\ldots \ldots \ldots \ldots \ldots \ldots \ldots$

Coproscopias $\ldots \ldots \ldots \ldots \ldots \ldots \ldots \ldots 7 . \ldots 707$

Positivas . . . . . . . . . . . 4.558

$\%$

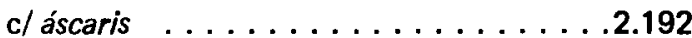

60.7

c/ tricúris . . . . . . . . . 2.798

29.2

c/ancilostomídeo $\ldots \ldots \ldots \ldots \ldots 265$

37.3

c/oxiúros . . . . . . . . . . . . . . . . . 104

3.5

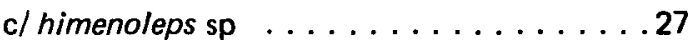

1.4

c/ Schist. mans . . . . . . . . . . . . 19

0.4

c/ameba cóli .............6622

0.3

c/giárdia . . . . . . . . . .633

8.3

8.4

Infectados c/ 1 esp. de paras

2.659

35.4

Infectados c/ 2 esp. de paras

1.522

20.3

Infectados c/ 3 esp. de paras

347

4.6

Infectados $\mathrm{c} / 4$ esp. de paras

0.4

Infectados $\mathrm{c} / 5$ esp. de paras

.29

0.0

Negativas

2.949

39.3

$\left({ }^{*}\right)$ Obs.: Escolas municipais (25), 1 escola para filhos de trabalhadores de uma firma de construção da Ponte Rio-Niterói, 1 Creche Casulo e uma Colônia de Férias do Corpo de Fuzileiros Navais, na Ilha do governador. 
Parasitismo Intestinal em Escolares - Ilha do Governador, RJ - 1977 - 1979

\begin{tabular}{|c|c|c|c|}
\hline Escola & Exames & $\begin{array}{l}\text { Positivos p/ } \\
\text { alguma esp. } \\
\text { de paras. }\end{array}$ & $\begin{array}{c}\% \text { de } \\
\text { positiv. }\end{array}$ \\
\hline 01 - Anita Garibaldi & 165 & 93 & 56.4 \\
\hline 02 - Álvaro Moreira & 224 & 108 & 48.2 \\
\hline $03-$ Cuba & 579 & 364 & 62.9 \\
\hline $04-$ Abeilard Feijó & 339 & 249 & 73.5 \\
\hline 05 - Rotary & 620 & 389 & 62.7 \\
\hline 06 - Sun Yat Sen & 336 & 175 & 52.1 \\
\hline 07 - Loreto Machado & 164 & 99 & 60.4 \\
\hline 08 - Alberto de Oliveira & 134 & 102 & 76.1 \\
\hline 09 - Pde José de Anchieta & 97 & 64 & 66.0 \\
\hline 10- Tte Antônio joão & 254 & 172 & 67.7 \\
\hline 11 - N. Sra do Loreto & 97 & 81 & 83.5 \\
\hline 12 - J. I. Pedro Mendes & 170 & 88 & 51.8 \\
\hline 13- Guilherme Presser & 128 & 102 & 79.7 \\
\hline 14- Holanda & 738 & 531 & 72.0 \\
\hline 15 - Jorn. Orlando Dantas & 271 & 176 & 64.9 \\
\hline 16- Rodrigo Otávio & 151 & 64 & 42,4 \\
\hline 17 - Costa Rica & 206 & 112 & 54.4 \\
\hline 18 - Cândido Portinári & 322 & 223 & 69.3 \\
\hline 19 - Didier B. Viana & 388 & 241 & 62.1 \\
\hline 20 - Belmiro Medeiros & 255 & 135 & 52.9 \\
\hline 21 - Dunshee de Abranches & 328 & 223 & 68.0 \\
\hline 22 - Profa Lavínia Dória & 245 & 114 & 46.5 \\
\hline 23 - Gurgel do Amaral & 201 & 87 & 43. 5 \\
\hline 24 - Maestro Fco Braga & 253 & 110 & 43.5 \\
\hline Centro Ocupacional Rotary & 116 & 72 & 62.1 \\
\hline Rio - Niterói & 169 & 116 & 68.6 \\
\hline Colônia de Férias C.F.N. & 541 & 255 & 47.1 \\
\hline Creche Casulo Dendê & 16 & 13 & 81.3 \\
\hline TOTAIS & 7.507 & 4.558 & 60.7 \\
\hline
\end{tabular}


Ascaríase em escolares - llha do Governador, RJ - 1977 - 1979

\begin{tabular}{|c|c|c|c|}
\hline Escola & Exames & $\begin{array}{l}\text { Positivos } \\
\text { p/áscaris }\end{array}$ & $\begin{array}{l}\% \text { de } \\
\text { positiv. }\end{array}$ \\
\hline 01 - Anita Garibaldi & 165 & 36 & 21.8 \\
\hline 02 - Álvaro Moreira & 224 & 39 & 17.4 \\
\hline 03 - Cuba & 579 & 170 & 29.4 \\
\hline 04 - Abeilard Feijó & 339 & 129 & 38.1 \\
\hline 05 - Rotary & 620 & 198 & 31.9 \\
\hline 06 - Sun Yat Sen & 336 & 65 & 19.3 \\
\hline 07 - Loreto Machado & 164 & 47 & 28.7 \\
\hline 08 - Alberto de Oliveira & 134 & 68 & 50.7 \\
\hline 09 - Pde José de Anchieta & 97 & 22 & 22.7 \\
\hline 10- Tte Antônio joão & 254 & 100 & 39.4 \\
\hline 11 - N. Sra do Loreto & 97 & 50 & 51.5 \\
\hline 12 - J. I. Pedro Mendes & 170 & 33 & 19.4 \\
\hline 13- Guilherme Presser & 128 & 65 & 50.8 \\
\hline $14-$ Holanda & 738 & 211 & 28.6 \\
\hline 15 - Jorn. Orlando Dantas & 271 & 94 & 34.7 \\
\hline 16 - Rodrigo Otávio & 151 & 25 & 16.6 \\
\hline 17 - Costa Rica & 206 & 44 & 21.4 \\
\hline 18 - Cândido Portinári & 322 & 126 & 39.1 \\
\hline 19 - Didier B. Viana & 388 & 104 & 26.8 \\
\hline 20 - Belmiro Medeiros & 255 & 65 & 25.5 \\
\hline 21 - Dunshee de Abranches & 328 & 137 & 41.8 \\
\hline 22 - Profa Lavínia Dória & 245 & 38 & 15.5 \\
\hline 23- Gurgel do Amaral & 201 & 22 & 10.9 \\
\hline 24 - Maestro Fco Braga & 253 & 55 & 21.7 \\
\hline Centro Ocupacional Rotary & 116 & 44 & 37.9 \\
\hline Rio - Niterói & 169 & 67 & 39.6 \\
\hline Colônia de Férias C.F.N. & 541 & 131 & 24.2 \\
\hline Creche Casulo Dendê & 16 & 7 & 43.8 \\
\hline TOTAIS & 7.507 & 2.192 & 29.2 \\
\hline
\end{tabular}


Tricuríase em escolares - Ilha do Governador, RJ - 1977 - 1979

\begin{tabular}{|c|c|c|c|}
\hline Escola & Exames & $\begin{array}{l}\text { Positivos } \\
\text { p/tricúris }\end{array}$ & $\begin{array}{c}\% \text { de } \\
\text { positiv. }\end{array}$ \\
\hline 01 - Anita Garibaldi & 165 & 61 & 37.0 \\
\hline 02 - Älvaro Moreira & 224 & 63 & 28.1 \\
\hline $03-$ Cuba & 579 & 223 & 38.5 \\
\hline 04 - Abeilard Feijó & 339 & 162 & 47.8 \\
\hline 05 - Rotary & 620 & 249 & 40.2 \\
\hline 06 - Sun Yat Sen & 336 & 102 & 30.4 \\
\hline 07 - Loreto Machado & 164 & 56 & 34.1 \\
\hline 08 - Alberto de Oliveira & 134 & 64 & 47.8 \\
\hline 09 - Pde José de Anchieta & 97 & 49 & 50.5 \\
\hline 10 - Tte Antônio João & 254 & 103 & 40.6 \\
\hline 11 - N. Sra do Loreto & 97 & 51 & 52.6 \\
\hline 12 - J.I. Pedro Mendes & 170 & 59 & 34.7 \\
\hline 13- Guilherme Presser & 128 & 82 & 64.1 \\
\hline 14- Holanda & 738 & 303 & 41.1 \\
\hline 15 - Jorn. Orlando Dantas & 271 & 117 & 43.2 \\
\hline 16-Rodrigo Otávio & 151 & 34 & 22.5 \\
\hline 17 - Costa Rica & 206 & 65 & 31.6 \\
\hline 18 - Cândido Portinári & 322 & 133 & 41.3 \\
\hline 19 - Didier B. Viana & 388 & 154 & 39.7 \\
\hline 20 - Belmiro Medeiros & 255 & 79 & 31.0 \\
\hline 21 - Dunshee de Abranches & 328 & 136 & 41.5 \\
\hline 22 - Profa Lavínia Dória & 245 & 67 & 27.3 \\
\hline 23- Gurgel do Amaral & 201 & 54 & 26.9 \\
\hline 24 - Maestro Fco Braga & 253 & 63 & 24.9 \\
\hline Centro Ocupacional Rotary & 116 & 44 & 37.9 \\
\hline Rio - Niterói & 169 & 70 & 41.4 \\
\hline Colônia de Férias C.F.N. & 541 & 155 & 28.7 \\
\hline Creche Casulo Dendê & 16 & 10 & 62.5 \\
\hline TOTAIS & 7.507 & 2.808 & 37.4 \\
\hline
\end{tabular}


Oxiuríase em escolares - Ilha do Governador, RJ - 1977 - 1979

\begin{tabular}{|c|c|c|c|}
\hline Escola & Exames & $\begin{array}{l}\text { Positivos } \\
\text { p/oxiúros }\end{array}$ & $\begin{array}{c}\% \text { de } \\
\text { positiv. }\end{array}$ \\
\hline 01 - Anita Garibaldi & 165 & - & - \\
\hline 02 - Álvaro Moreira & 224 & 1 & 0.4 \\
\hline 03 - Cuba & 579 & 16 & 2.8 \\
\hline $04-$ Abeilard Feijó & 339 & 6 & 1.8 \\
\hline 05 - Rotary & 620 & 11 & 1.8 \\
\hline 06 - Sun Yat Sen & 336 & 10 & 3.0 \\
\hline 07 - Loreto Machado & 164 & 1 & 0.6 \\
\hline 08 - Alberto de Oliveira & 134 & - & - \\
\hline 09 - Pde José de Anchieta & 97 & 1 & 1.0 \\
\hline 10- Tte Antônio João & 254 & 3 & 1.2 \\
\hline 11 - N.Sra do Loreto & 97 & - & - \\
\hline 12 - J.I. Pedro Mendes & 170 & 1 & 0.6 \\
\hline 13- Guilherme Presser & 128 & 1 & 0.8 \\
\hline 14-- Holanda & 738 & 8 & 1.1 \\
\hline 15 - Jorn. Orlando Dantas & 271 & 9 & 3.3 \\
\hline 16- Rodrigo Otávio & 151 & - & - \\
\hline 17 - Costa Rica & 206 & 4 & 1.9 \\
\hline 18 - Cândido Portinári & 322 & 4 & 1.2 \\
\hline 19 - Didier B. Viana & 388 & 10 & 2.6 \\
\hline 20 - Belmiro Medeiros & 255 & 5 & 2.0 \\
\hline 21 - Dunshee de Abranches & 328 & 2 & 0.6 \\
\hline 22 - Profa Lavínia Dória & 245 & 2 & 0.8 \\
\hline 23 - Gurgel do Amaral & 201 & 3 & 1.5 \\
\hline 24 - Maestro Fco Braga & 253 & 2 & 0.8 \\
\hline Centro Ocupacional Rotary & 116 & - & - \\
\hline Rio - Niterói & 169 & 1 & 0.6 \\
\hline Colônia de Férias C.F.N. & 541 & 5 & 0.9 \\
\hline Creche Casulo Dendê & 16 & - & - \\
\hline TOTAIS & 7.507 & 106 & 1.4 \\
\hline
\end{tabular}


Giardíase em escolares - Ilha do Governador, RJ - $1977 \cdot 1979$

\begin{tabular}{|c|c|c|c|}
\hline Escola & Exames & $\begin{array}{l}\text { Positivos } \\
\text { p/giárdia }\end{array}$ & $\begin{array}{c}\% \text { de } \\
\text { positiv. }\end{array}$ \\
\hline 01 - Anita Garibaldi & 165 & 15 & 9.1 \\
\hline 02 - Álvaro Moreira & 224 & 15 & 6.7 \\
\hline 03 - Cuba & 579 & 62 & 10.7 \\
\hline 04 - Abeilard Feijó & 339 & 44 & 13 \\
\hline 05 - Rotary & 620 & 50 & 8.1 \\
\hline 06 - Sun Yat Sen & 336 & 30 & 8.9 \\
\hline 07 - Loreto Machado & 164 & 23 & 14.0 \\
\hline 08 - Alberto de Oliveira & 134 & 13 & 9.7 \\
\hline 09 - Pde José de Anchita & 97 & 9 & 9.3 \\
\hline 10- Tte Antônio João & 254 & 26 & 10.2 \\
\hline 11 - N. Sra do Loreto & 97 & 8 & 8.2 \\
\hline 12 - J.I. Pedro Mendes & 170 & 14 & 8.2 \\
\hline 13- Guilherme Presser & 128 & 7 & 5.5 \\
\hline 14- Holanda & 738 & 58 & 7.9 \\
\hline 15 - Jorn. Orlando Dantas & 271 & 16 & 5.9 \\
\hline 16-Rodrigo Otávio & 151 & 9 & 6.0 \\
\hline 17 - Costa Rica & 206 & 25 & 12.1 \\
\hline 18 - Cândido Portinári & 322 & 23 & 7.1 \\
\hline 19 - Didier B. Viana & 388 & 27 & 7.0 \\
\hline 20- Belmiro Medeiros & 255 & 20 & 7.8 \\
\hline 21 - Dunshee de Abranches & 328 & 20 & 6.1 \\
\hline 22 - Profa Lavínia Dória & 245 & 30 & 12.2 \\
\hline 23 - Gurgel do Amaral & 201 & 15 & 7.5 \\
\hline 24 - Maestro Fco Braga & 253 & 9 & 3.6 \\
\hline Centro Ocupacional Rotary & 116 & 5 & 4.3 \\
\hline Rio - Niterói & 169 & 16 & 9.5 \\
\hline Colônia de Férias C.F.N. & 541 & 43 & 7.9 \\
\hline Creche Casulo Dendê & 16 & 2 & 12.5 \\
\hline TOTAIS & 7.507 & 634 & 8.4 \\
\hline
\end{tabular}


Parasitoses Intestinais - Itha do Governador, RJ - 1977 - 1979

\begin{tabular}{|c|c|c|c|c|c|c|}
\hline \multirow{3}{*}{ Escola } & \multirow{3}{*}{ Exames } & \multirow[b]{3}{*}{1 paras. } & \multicolumn{2}{|c|}{ Positivos } & \multirow[b]{3}{*}{4 oaras. } & \multirow{3}{*}{ Total } \\
\hline & & & & & & \\
\hline & & & 2 paras. & 3 paras. & & \\
\hline 01 & 165 & 57 & 33 & 3 & - & 93 \\
\hline 02 & 224 & 84 & 21 & 3 & - & 108 \\
\hline 03 & 579 & 211 & 129 & 19 & 5 & 354 \\
\hline 04 & 339 & 120 & 98 & 28 & 3 & 249 \\
\hline 05 & 620 & 209 & 142 & 37 & 1 & 389 \\
\hline $06+$ & 336 & 120 & 48 & 5 & 2 & 175 \\
\hline 07 & 164 & 63 & 27 & 9 & - & 99 \\
\hline 08 & 134 & 42 & 42 & 16 & 2 & 102 \\
\hline 09 & 97 & 38 & 22 & 4 & - & 64 \\
\hline 10 & 254 & 94 & 61 & 17 & - & 172 \\
\hline 11 & 97 & 47 & 25 & 8 & 1 & 81 \\
\hline 12 & 170 & 64 & 23 & 1 & - & 88 \\
\hline 13 & 128 & 42 & 49 & 11 & - & 102 \\
\hline 14 & 738 & 268 & 208 & 53 & 2 & 531 \\
\hline 15 & 271 & 88 & 63 & 20 & 5 & 176 \\
\hline 16 & 151 & 55 & 9 & - & - & 64 \\
\hline 17 & 206 & 67 & 36 & 9 & - & 112 \\
\hline 18 & 322 & 127 & 76 & 16 & 4 & 223 \\
\hline 19 & 388 & 148 & 78 & 15 & - & 241 \\
\hline 20 & 255 & 88 & 38 & 8 & 1 & 135 \\
\hline 21 & 328 & 119 & 83 & 20 & 1 & 223 \\
\hline 22 & 245 & 87 & 25 & 2 & - & 114 \\
\hline 23 & 201 & 70 & 14 & 3 & - & 87 \\
\hline 24 & 253 & 84 & 24 & 2 & - & 110 \\
\hline C.O. Rotary & 116 & 46 & 22 & 4 & - & 72 \\
\hline Rio-Niterói & 169 & 63 & 38 & 14 & 1 & 116 \\
\hline Col. Férias & 541 & 152 & 82 & 19 & 2 & 255 \\
\hline Creche Dendê & 16 & 6 & 6 & 1 & - & 13 \\
\hline \multirow{2}{*}{ TOTAIS } & 7.507 & 2.659 & 1.522 & 347 & 30 & 4.558 \\
\hline & $\%$ & 58.3 & 33.4 & 7.6 & 0.7 & 100 \\
\hline
\end{tabular}

Obs.: + 1 aluno com 5 parasitas. 
Parasitismo intestinal em escolas - Itha do Governador, RJ - 1977 - 1979

\begin{tabular}{|c|c|c|c|c|c|c|c|c|c|c|}
\hline \multirow{2}{*}{$\begin{array}{l}N^{O} \text { de } \\
\text { Ordem }\end{array}$} & \multirow{2}{*}{ Escolas } & \multirow[b]{2}{*}{ 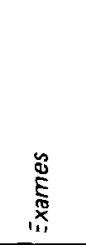 } & \multicolumn{6}{|c|}{ HELMINTOS } & \multicolumn{2}{|c|}{$\begin{array}{c}\text { PROTOZOÁ- } \\
\text { RIOS }\end{array}$} \\
\hline & & & 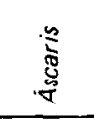 & 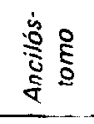 & $\stackrel{n}{3}$ & : & 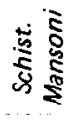 & 造定 & 8 & 雾 \\
\hline 01 & Anita Garibaldi & 165 & 36 & 1 & 61 & - & - & - & 17 & 15 \\
\hline 02 & Álvaro Moreira & 224 & 39 & 4 & 63 & 1 & 4 & 1 & 9 & 15 \\
\hline 03 & Cuba & 579 & 170 & 14 & 223 & 16 & - & 5 & 56 & 62 \\
\hline 04 & Abeilard Feijó & 339 & 129 & 25 & 162 & 6 & 1 & - & 40 & 44 \\
\hline 05 & Botary & 620 & 198 & 27 & 249 & 11 & 6 & 2 & 64 & 50 \\
\hline 06 & Sun Yat Sen & 336 & 65 & 9 & 102 & 10 & - & - & 24 & 30 \\
\hline 07 & Loreto Machado & 164 & 47 & 1 & 56 & 1 & - & - & $\begin{array}{c}96 \\
16\end{array}$ & $\begin{array}{l}27 \\
23\end{array}$ \\
\hline 08 & Alberto de Oliveira & 134 & 68 & 14 & 64 & - & - & - & 23 & 13 \\
\hline 09 & Padre José de Anchieta & 97 & 22 & 5 & 49 & 1 & - & - & 9 & 9 \\
\hline 10 & Tenente Antônio João & 254 & 100 & 7 & 103 & 3 & - & - & 28 & 26 \\
\hline 11 & Nossa Senhora do Loreto & 97 & 50 & 9 & 51 & - & - & - & 7 & 8 \\
\hline 12 & J. I. Pedro Lima Mendes & 170 & 33 & 1 & 59 & 1 & - & - & 5 & 14 \\
\hline 13 & Guilherme Presser & 128 & 65 & 8 & 82 & 1 & - & - & 10 & 7 \\
\hline 14 & Holanda & 738 & 211 & 37 & 303 & 8 & 2 & 3 & 77 & 58 \\
\hline 15 & Jorn. Orlando Dantas & 271 & 94 & 26 & 117 & 9 & 3 & 2 & 26 & 16 \\
\hline 16 & Rodrigo Otávio & 151 & 25 & 1 & 34 & - & - & - & 8 & 9 \\
\hline 17 & Costa Rica & 206 & 44 & 6 & 65 & 4 & - & - & 12 & 25 \\
\hline 13 & Cãndido Portinári & 322 & 126 & 19 & 133 & 4 & 2 & - & 23 & 23 \\
\hline 19 & Didier B. Viana & 388 & 104 & 15 & 154 & 10 & - & 2 & 34 & 27 \\
\hline 20 & Belmiro Medeiros & 255 & 65 & 3 & 79 & 5 & - & - & 19 & 20 \\
\hline 21 & Dunshee de Abranches & 328 & 137 & 19 & 136 & 2 & - & 1 & 34 & 20 \\
\hline 22 & Profă Lavínia Dória & 245 & 38 & - & 67 & 2 & - & - & 6 & 30 \\
\hline 23 & Gurgel do Amaral & 201 & 22 & - & 54 & 3 & - & 1 & 12 & 15 \\
\hline 24 & Maestro Francisco Braga & 253 & 55 & 1 & 63 & 2 & - & - & 7 & 9 \\
\hline 25 & C. C. Rotary & 116 & 44 & 1 & 44 & - & - & 1 & 4 & 5 \\
\hline 26 & Rio -- Niterói & 169 & 67 & 4 & 70 & 1 & - & 3 & 20 & 16 \\
\hline 27 & Colônia de Ferias C.F.N. & 541 & 131 & 6 & 155 & 5 & 1 & 8 & 32 & 43 \\
\hline 28 & Creche Casulo Dendê & 16 & 7 & - & 10 & - & - & - & - & 2 \\
\hline 28 & TOTAL & 7.507 & 2.192 & 263 & 2.808 & 106 & 19 & 29 & 622 & 634 \\
\hline- & $\%$ & - & 29,19 & 3.50 & 37,40 & 1,41 & 0,25 & 0,38 & 8,28 & 8,44 \\
\hline
\end{tabular}


Himenolepíase em escolares - Ilha do Governador, RJ - 1977 - 1979

\begin{tabular}{llcl}
\hline \multicolumn{1}{c}{ Escola } & Exames & $\begin{array}{c}\text { Positivos } \\
\text { p/ himenoleps }\end{array}$ & $\begin{array}{l}\% \text { de } \\
\text { positiv. }\end{array}$ \\
\hline $02-$ Álvaro Moreira & 224 & 1 & 0.4 \\
$03-$ Cuba & 579 & 5 & 0.9 \\
$05-$ Rotary & 620 & 2 & 0.3 \\
14- Holanda & 738 & 3 & 0.4 \\
15- Jorn. Orlando Dantas & 271 & 2 & 0.7 \\
19- Didier B. Viana & 388 & 2 & 0.5 \\
21- Dunshee de Abranches & 328 & 1 & 0.3 \\
23- Gurgel do Amaral & 201 & 1 & 0.5 \\
Centro Ocupacional Rotary & 116 & 1 & 0.9 \\
Colônia de Férias C.F.N. & 541 & 8 & 1.5 \\
Rio - Niterói & 169 & 3 & 1.8 \\
\hline
\end{tabular}

TOTAIS

Obs: As demais Escolas foram negativas. 